\title{
Review of drug education campaign
}

\section{Health Education Authority drugs education campaign}

\section{Health Risks of 'E', LSD and Speed - Know the Score}

The latest stage of the Health Education Authority drugs education campaign comprises print and radio advertisements aimed at stimulant and hallucinogen users on the club scene. It is linked to fact sheet advertisements for parents and the National Drug Helpline. The explicit aim is to encourage a rethinking of drug use by providing credible health information.

It is right to provide drug users with information to allow them to make informed choices and minimise risks, but these materials do not do that. There is a heavy emphasis on dreadful consequences. For example, the LSD print advertisement reminded me of a 19th century tract on the dangers of onanism. LSD, we learn, is bad news. It leads to impaired eyesight, nightmarish flashbacks, visual, auditory, gustatory and somatic hallucinations and unstoppable bad trips. There is a claim that tiny amounts of LSD can trigger off long-term serious mental illness, which is almost certainly untrue. Although the press release claims balance, there is little or none. The print advertisements are drug scare tactics in the discredited tradition of "Reefer Madness".

The radio advertisements encourage users to contact the drugs helpline. Some use scare tactics (e.g. inept musical impression of a bad trip), some illustrate clubbers' ignorance by following soundbites with a voice-over, "True" or
"False". Unfortunately, the voice-over is unrellable. Regarding LSD, a user states "You have to take loads to get an effect", response - "False"; well, true actually. Modern LSD doses are tiny compared with those of the 1970s, and to have a full blown psychedelic experience, you do need to take several. Each advertisement closes cringingly with the punning catchphrase "Know the Score".

Being middle-aged and cynical, I asked my SHO's opinion. He is a regular club goer and underground dance music devotee. He agreed that the campaign would have no credibility for the club drug user. Significantly, one part of the speed radio advertisement raised a wry smile of recognition - "It gives you a jittery jaw - you talk rubbish to anyone". If such campaigns are to be successful, they must resonate with users' experience and take a more neutral stance. Paranoid experiences are common on speed and are dose related. This information would be more useful than non-specific warnings of mental illness.

Health Education campaigns have a history of political interference and a more neutral stance might be viewed as being soft on drugs. However, insulting the intelligence of users is not effective, and an administration that was serious about public health and drugs would surely embrace a true harm reduction approach, regardless of marginal political embarrassment.

R. G. POOLE, Consultant in General Psychiatry, North Mersey Community (NHS) Trust, Liverpool L14 3PU 